\title{
Madres combatientes o la afirmación de la figura de la "buena madre" *
}

\author{
Patricia Ramírez Parra
}

Universidad de Antioquia, Medellín, Colombia. Email: patriciaramirez@iner.udea.edu.co

Resumen: Este artículo presenta una reflexión sobre aquellas mujeres que siendo madres “optaron” por vincularse a las Autodefensas Unidas de Colombia, convirtiéndose la gran mayoría en "obreras de la guerra” para cumplir la función materna de no dejar morir a sus hijos. Son madres combatientes que fueron a la guerra para luchar por sus hijos/as, sacrificando su vida por ese otro que una vez hizo parte de ella. Intento demostrar que dichas madres combatientes, no transgreden las normas de la maternidad hegemónica. Transgreden sí, la visión estereotipada de género, según la cual se considera a la mujer esencialmente "pacífica”. Pero no son efectivamente transgresoras de los ideales asociados a la maternidad vista fundamentalmente como esencia, como un hecho biológico e individual. Finalmente se hace una apuesta por repensar la(s) maternidad(es) en una sociedad en (pos) conflicto como la colombiana.

Palabras clave: maternidad, madres combatientes, guerra, paramilitares, política de la localización.

\section{Combatant mothers or the affirmation of the figure of the "good mother"}

\begin{abstract}
This article presents an analysis on women, who being mothers "opted" to enrol with the United Self-Defence Forces of Colombia, the majority of them turning into "labourers of war" in order to fulfil their maternal function of securing the survival of their offspring. They are combatant mothers, who went to war to fight for their children, sacrifying their own life for that other being that once was a part of her. I try to show that those combatant mothers do not transgress the norms of hegemonic maternity. Nonetheless they transgress the gendered stereotypical vision considering women to be essentially "peaceful”. But they are not really transgressors to the ideals associated with motherhood, seen fundamentally as essence, as a biological and individual fact. Finally, I propose to revise motherhood in a (post)conflict society, such as Colombia.
\end{abstract} politics.

Key words: motherhood, combatant mothers, war, paramilitars, location's

\section{Mães combatentes ou a afirmação do conceito de "boa mãe"}

Resumo: Este artigo apresenta uma reflexão sobre as mulheres que sendo mães “escolheram” enrolar-se às Forças de Defesa da Colômbia, se tornando uma grande maioria em "trabalhadores da guerra” para cumprir a função materna para não deixar seus filhos morrer. Eles são mães lutadoras que foram à guerra para lutar por seus filhos, sacrificando sua vida para esse outro que foi parte dela. Tento 
mostrar que essas mães combatentes, não violam as normas da maternidade hegemônica. Violá-la, a visão estereotipada de gênero, segundo o qual as mulheres são consideradas essencialmente "pacíficas". Mas eles não são realmente transgressoras dos ideais associados com a maternidade, principalmente visto essencialmente como um evento biológico e individual. Finalmente, presenta-se a aposta de repensar a(s) maternidade(s) em uma sociedade (pós)conflito como Colombia. do lugar.

Palavras-chave: maternidade, mães, soldados, guerra, política paramilitar

Las instituciones de la sociedad y del Estado reproducen a las mujeres como madres Marcela Lagarde

\section{Presentación}

Gran parte de las mujeres-madres desmovilizadas de los grupos de Autodefensa en Colombia AUC -llamados comúnmente paramilitares- se han visto envueltas en la guerra sin haber sido partícipes de las decisiones que dieron origen a estos grupos armados ilegales, y más aún, sin comprender las denominadas causas históricas y objetivas de la confrontación armada en Colombia.

La participación de las mujeres en los distintos ejércitos, bien sea como combatientes; en actividades logísticas, de inteligencia, políticas, de servidumbre sexual, o en trabajo doméstico, pueden explicarse por múltiples razones entre las que se cuentan: socio-económicas, subjetivas y políticas. Como elemento central para el desarrollo de este artículo, me interesan aquellas que tienen que ver con las razones socioeconómicas, según las cuales, las mujeres encuentran en la milicia una ocupación alternativa. A veces, en contextos específicos, en espacios y tiempos particulares, la vinculación a los grupos armados ilegales se presenta como la única ocupación disponible, como lo han demostrado investigaciones realizadas por Vanessa Farr (2002) en África; y en Colombia, las realizadas por Londoño y Nieto (2005; 2007) y Londoño et al (2010).

En este artículo mi interés se centra en aquellas mujeres que siendo madres "decidieron" u "optaron” por vincularse a las AUC, convirtiéndose la gran mayoría en “obreras de la guerra” para cumplir la función materna de no dejar morir a sus hijos. Son mujeres-madres que en adelante denominaré madres combatientes -no necesariamente porque su participación en la guerra haya sido como soldados- sino porque participaron en ella para luchar por sus hijos/as.

Intentaré demostrar que dichas madres combatientes, no transgreden 
las normas de la maternidad hegemónica. Transgreden sí, la visión estereotipada de género, según la cual se considera a la mujer esencialmente "pacífica”. Pero no podemos afirmar que sean transgresoras de los ideales asociados a la maternidad vista fundamentalmente como esencia, como un hecho biológico e individual.

Ellas se van a la guerra, precisamente en cumplimiento de las funciones y los valores asociados a esta manera de concebir la maternidad. Es el amor materno, el sacrificio por los hijos/as, en cumplimiento de la función nutricia de la maternidad la que moviliza su acción de ingreso al grupo armado, en este caso, paramilitar. Como madres tienen la obligación de mantener a sus hijos/as en la vida e impedir su muerte, como lo veremos en algunos de los testimonios de madres excombatientes desmovilizadas de las Autodefensas recabados en sendas investigaciones realizadas en Colombia entre 2007 y 2010.

Aquellas mujeres como muchas en el mundo, han sido socializadas en lo que Gayatri Spivak denomina la Heteronormatividad reproductiva (HNR), aquella según la cual una mujer solo existe para tener descendencia (legítima) ${ }^{1}$. La HNR es la institución más antigua y extendida en el mundo ${ }^{2}$. Para muchas mujeres, y entre éstas las madres combatientes, la maternidad y el amor maternal ha sido asumido como un asunto inherente a su ser, constituyéndose en el núcleo fundamental de la identidad femenina (Lagarde 2006: 251).

Este artículo está estructurado en tres partes. La primera contiene un recorrido por la concepción histórica de la maternidad, que nos permita comprender las concepciones propias sobre la maternidad que tienen algunas de las madres combatientes, hoy desmovilizadas de los grupos paramilitares. En la segunda parte, me ocuparé de mostrar quiénes son y desde dónde hablan estas madres para explicar por un parte, sus razones de ingreso al paramilitarismo en Colombia; cuáles son a su juicio las causas de la confrontación armada y por último, quienes son para ellas, los responsables de la misma. Apoyada en la política feminista de la localización de Adrianne Rich, intento poner sobre la mesa de debate elementos que nos permitan antes que juzgar la “elección” de éstas mujeres, comprender su actuación en un momento y contexto determinado. En la tercera parte y a modo de reflexión, intentaré presentar algunos elementos que nos permitan debatir sobre el ejercicio de la maternidad en una sociedad en (pos) conflicto como la colombiana donde no se vislumbra un tránsito real de la guerra a la paz, porque nuestro país requiere con urgencia una paz distinta y distante del simple silenciamiento de los fusiles; que se acerque cada vez más a la efectiva realización de un Estado de Derecho, Democrático, Pluralista, que hagan posible un país con justicia social, justicia de género y justicia cultural, y en el cual exista el respeto total por los derechos humanos, incluidos los derechos sexuales y reproductivos de las mujeres colombianas. 


\section{Maternidad: historia de un concepto}

En su libro Los cautiverios de las mujeres: madresposas, monjas, putas, presas y locas, Marcela Lagarde ha señalado que, todas las culturas incluyen concepciones (representaciones, teorías, normas, creencias, valoración) dominantes sobre la maternidad, y en todas las sociedades se desarrollan políticas hegemónicas de maternidad. (Lagarde 2006: 250). La maternidad no es un concepto que pueda ser pensado sin historicidad y sin una ubicación socio-espacial. Ésta ha estado profundamente influenciada por la cultura, la sociedad, las instituciones y el Estado. ¿Cuáles han sido para el caso de la cultura occidental, las concepciones de maternidad? ¿Cómo ha cambiado el concepto?

En su célebre libro El segundo sexo, Simone de Beauvoir nos presenta un recorrido sobre la historia de La Mujer, a partir del cual podemos inferir algunas de las concepciones y cambios producidos sobre la noción de maternidad. Por su parte, María Elisa Molina, en su artículo titulado "Transformaciones Histórico Culturales del Concepto de Maternidad y sus Repercusiones en la Identidad de la Mujer”, nos ofrece un completo recorrido por lo que ha sido la evolución histórica de la noción de la maternidad, particularmente en relación con la imagen de la mujer y las nociones de crianza. Para ella, la maternidad ha sido tal vez la investidura más poderosa para la autodefinición y autoevaluación de cada mujer, incluso aún de aquellas que no son madres (Molina, 2006:93), planteamiento cercano al de la HNR de Spivak arriba mencionado.

De la mano de Simone de Beauvoir y Molina iniciaré el tránsito por el concepto de maternidad.

\section{De la función sagrada de la maternidad al principio masculino creador}

En El segundo sexo, Simone de Beauvoir nos recuerda que con el paso del nomadismo al sedentarismo y el surgimiento de la agricultura, el hombre empieza a pensar en ese mundo y a pensarse a sí mismo, y la diferencia sexual se refleja en la estructura de la colectividad. La mujer en las nacientes comunidades agrícolas, aparece revestida de un extraordinario prestigio, el cual florece ligado a la importancia que cobra el niño en una civilización basada en el trabajo de la tierra. Cuando los nómadas se instalan en un territorio, se apropian del mismo, aparece la propiedad bajo forma colectiva, que exige de sus poseedores una descendencia. Es en este contexto donde la maternidad se convierte en una función sagrada. (Beauvoir 2005: 67)

Los niños representan la existencia y la prolongación de la comunidad. En razón a ello la madre resulta imprescindible... 
Ella es quien conserva y nutre al germen en su seno y, por consiguiente, es a través de ella como se propaga en el mundo visible la vida del clan. Así es como ella se ve representando un papel de primer orden. (Ibíd.: 68)

En esta era primitiva podemos decir siguiendo a Beauvoir, que la Naturaleza se le presenta al hombre agricultor como una madre; la tierra es mujer; y la mujer está habitada por las mismas oscuras potencias de la tierra.

$\mathrm{Al}$ contrario de los hombres primitivos, en la cultura griega, es el principio masculino el verdadero creador, tal y como proclamaron Esquilo, Aristóteles e Hipócrates, al señalar que de dicho principio nacen la forma, el número y el movimiento. Por Démeter, diosa de la agricultura y las cosechas, se multiplican las espigas, pero el origen de la espiga y su verdad están en Zeus; la fecundidad de la mujer sólo se considera como una virtud pasiva. (Ibíd.: 144)

\section{Entre la pecadora y la salvadora o el legado judeocristiano de la maternidad}

De acuerdo con el mito de la creación, Dios creó al hombre, y de su costilla creó a la mujer, y después de haber sido creada, la Mujer es la culpable de la desobediencia del hombre, y en consecuencia dirá Dios:

Multiplicaré en gran manera los dolores de tus preñeces; con dolor darás a luz los hijos; y tu voluntad será sujeta a tu marido, y él se enseñoreará de ti. (Génesis 3:16)

Pero antes de ser Eva, -Madre de todos los vivientes-, la Mujer es compañera de Adán. Su nacimiento no fue autónomo, no fue creada como fin en sí misma, sino para salvar a Adán de su soledad. En palabras de Beauvior, ella tiene en su esposo su origen y su fin, es su complemento sobre el modo de lo inesencial. (Ibíd.: 141)

En el nuevo testamento, San Pablo a los Efesios consagra el sometimiento de la mujer al hombre; dice el apóstol: las casadas estén sujetas a sus propios maridos, como al Señor; porque el marido es cabeza de la mujer, así como Cristo es cabeza de la iglesia... (Efesios 5: 22) Se establece así una relación de dominación-subordinación que la Iglesia se encargará de perpetuar.

Además de Eva, la mujer es al mismo tiempo en la tradición judeocristiana Virgen María. En oposición a la pecadora, mediadora de la condenación, María se erige como la mediadora de la salvación, y es a través de su figura como la mujer es integrada a la sociedad porque...

Ella es indispensable para su prosperidad. La virgen consagrada y la 
esposa casta y dócil con una vida de devoción al hijo ofrecen un marco para revalorizar lo femenino necesario para la vida y el orden en la sociedad. La figura de la Virgen María constituye una fuente primordial de identificación y revalorización de la mujer. (Molina 2006: 95).

El Marianismo tiene una importancia fundamental para explicar y comprender la construcción de la identidad genérica de buena parte ${ }^{3}$ de las mujeres en América Latina. Según la antropóloga chilena Sonia Montecino citada por Sanhueza (2005: 155), el ícono mariano nos permite comprender la reproducción de ciertos valores ligados a lo femenino, y que se constituyen en estereotipos de nuestra identidad genérica, a saber: espiritualidad, pureza, abnegación, sacrificio, virginidad, maternidad, etc.

En América Latina el catolicismo y la religiosidad popular son elementos claves de nuestro ethos cultural, los cuales marcan de una u otra manera las ideas y percepciones sobre la maternidad.

\section{Procreadoras y reproductoras}

De acuerdo con Molina (2006: 95), la Edad Media entre los siglos IX y XIV en Europa, es probablemente uno de los periodos más misóginos de la historia. Hecho que tiene su sustento en la concepción de Eva, como representante del pecado original, el cual a su vez convierte al cuerpo en enemigo del alma.

En consecuencia a partir de la Edad Media el tener un cuerpo ha sido considerado en la mujer como una vergüenza, por tanto en el Medioevo la virginidad cobra una importancia crucial, y se consagra la tríada mujer-esposa-madre que sustenta un discurso sobre la maternidad dominado por los aspectos más fisiológicos de la función: procreación, gestación, parto y amamantamiento, reafirmando para la madre la función puramente nutritiva, que la naturaleza le ha asignado visiblemente (Molina 2006: 96). De allí se desprende que hasta nuestros días, la Iglesia (Católica) siga pregonando que las relaciones sexuales sólo se justifican para la prolongación de la especie.

Es en tanto Madre -en legítima unión- como la mujer es amada y respetada. En el corazón de la Edad Media, se yergue la más acabada imagen de la mujer propicia a los hombres: el rostro de la Madre de Cristo se circunda de gloria. (Beauvoir 2005: 174)

Finalmente dos elementos que no podemos pasar desapercibidos en esta época, tienen que ver, uno con la glorificación del amor materno que aparece como algo incuestionable; dos con el insignificante papel pedagógico de la madre en la educación de los hijos. Superados los cuidados biológicos de la primera infancia, la atención suele desplazarse hacia el padre, quien aparece como el responsable de la educación de la prole, mien- 
tras que los temas de salvación espiritual y control de compartimientos morales son atribuciones maternas, fundamentalmente en lo que tiene que ver con la vigilancia y el control de la sexualidad de las hijas para preservar la virginidad. (Molina 2006: 96)

\section{Madres sin poder}

Durante la Era Romántica se continúa considerando la maternidad como función procreadora. Los infantes son vistos como peligrosos, extrañas criaturas capaces de hacerse daño a sí mismos y a los demás, de donde se deriva que el castigo físico este aprobado como disciplina y el cuidado es entregado a terceros, que generalmente son mujeres porque ocupan un lugar inferior. (Ibídem)

Ad portas de la Revolución Francesa, en el siglo XVIII ciertos grupos de la Burguesía comienzan a considerar a los infantes como seres que necesitan protección. Rousseau intérprete de la burguesía, consagra la mujer a su marido y a la maternidad. "Toda la educación de la mujer debe ser relativa al hombre... La mujer está hecha para ceder al hombre y para soportar sus injusticias”, afirmará Rousseau citado por Beauvoir (2005: 98)

Como nos recuerda la misma autora, cuando el 28 brumario de 1793, y ante la entrada de la Sociedad de Mujeres Republicanas y Revolucionarias acompañada de otras mujeres, el procurador Chaumette expresó: ¿Desde cuándo está permitido a las mujeres abjurar de su sexo y convertirse en hombres?... [La Naturaleza] ha dicho a la mujer: 'Sé mujer. Los cuidados de la infancia, los detalles domésticos, las diversas inquietudes de la maternidad: he ahí tus labores’. (Ibíd.: 100) En tanto fenómeno natural, la maternidad no confiere a las mujeres ningún poder.

\section{Madres en la modernidad}

En el siglo XVIII empieza a desarrollarse en Francia la tendencia maltusiana de control de la población. Las familias acomodadas y luego el conjunto de la población comienzan a considerar necesario limitar el número de hijos de acuerdo con los recursos de los padres, y los procedimientos anticonceptivos empiezan a introducirse en las costumbres. El preservativo utilizado fundamentalmente como antivenéreo se propaga como anticonceptivo a mediados del siglo XIX. (Beauvoir 2005: 111). Durante el siglo XIX la mujer se independiza de la Naturaleza, conquista el dominio de su cuerpo, y al sustraerse en gran parte de la tareas de la reproducción, puede asumir el papel económico que se le ofrece en la revolución industrial y que le asegurará la conquista de su persona en su totalidad.

La razón instrumental y el desarrollo científico domina no sólo la medicina, la administración pública, sino también el mundo privado de lo 
doméstico donde tiene cabida la crianza de los infantes. El Estado en Europa entra a formar parte de las funciones de crianza desarrollando una institucionalidad para tales fines (leyes sobre escolaridad, jardines infantiles, tribunales de menores), lo que se presenta de manera mucho más tardía en América Latina ${ }^{4}$.

Entradas en el siglo XX las mujeres madres en los Estados Unidos defienden su valor como encargadas de la formación de los futuros ciudadanos de la república. Nos encontramos frente a un concepto de la Maternidad como moral, según la cual madre tiene la tarea de ofrecer apoyo moral y social a su esposo e hijos; en este sentido su aporte al bienestar social es reconocido. La presencia de la Madre es irremplazable, su tarea requiere dedicación, conocimiento y capacidad de amor; el padre no aparece como importante. La atención explícita del carácter moral del niño va ampliándose a una dedicación a su desarrollo físico, emotivo, cognitivo y conductual. (Molina 2006: 97). Como nos advierte la autora citada, en esta época la figura de la madre idealizada, resulta altamente peligrosa, pues pone en la mujer-madre la responsabilidad del comportamiento bien sea positivo o negativo de los/las hijos/as. De dónde se desprende una relación causal entre crianza y desarrollo, dando lugar a las posiciones de buenas y malas madres. El amor maternal se entiende como inherente a la mujer, y la maternidad como su objetivo central.

\section{Madres por opción, no por obligación}

La lucha de las mujeres y particularmente del movimiento feminista por sus derechos sexuales y reproductivos, el replanteamiento de los procesos de socialización y crianza donde se invita a los hombres a paternar, la lucha por una distribución equitativa de las tareas domésticas, son fundamentales para comprender los cambios en la visión de la maternidad en la contemporaneidad. De una maternidad omnipresente en la vida de las mujeres y una crianza centrada en ellas, pasamos a una maternidad que se posterga o no se realiza. Una crianza un poco más compartida, y apoyada por el Estado, que comienzan a conceder además de la licencia de maternidad, licencia de paternidad.

En la era posmodernidad la maternidad se entiende como un fenómeno sociocultural. A partir de lo planteado por Marcela Lagarde podemos hablar de maternidad en plural. Son maternidades socialmente vividas que se producen y reproducen de maneras distintas. Los esfuerzos para situar la maternidad en el contexto histórico y cultural fueron muchos; las concepciones que reproducen hoy la maternidad no son idénticas ni tampoco las maneras como las mujeres las viven en todos los tiempos y espacios.

Para terminar este acápite, podemos decir con Molina que:

En el contexto en que se desenvuelve la madre posmoderna con nuevos parámetros de evaluación, con nuevas formas de participa- 
ción en el juego social, la maternidad queda menos señalada como la única condición definitorio del sí mismo de la mujer y de su valor como persona. (Ibíd.: 101)

\section{Decisiones y concepciones localizadas: madres combatientes hablan desde la periferia}

Es desde la política feminista de la localización planteada por Adrianne Rich, que reconoce la importancia del lugar en la vida de los individuos, en tanto hacemos parte de un contexto histórico, un tiempo y un lugar que contribuye a crear nuestra personalidad (Rich citada por Roberson 2010: 223); y la teoría de la posicionalidad de Linda Alcoff según la cual la identidad y la subjetividad de las mujeres se constituyen según la posición que ocupen ${ }^{5}$, como podemos comprender los valores asociados a la noción de maternidad que tienen las madres excombatientes y las razones que las llevaron a tomar la decisión de vincularse a los grupos paramilitares, ya que la mirada sobre la realidad está influenciada por el lugar desde el que hablan y la posición que ocupan las personas, en este caso las mujeres - madres.

Considerar entonces los lugares y las posiciones que ocupan las mujeres según las categorías identitarias de género, raza/etnia, clase, religión y procedencia resulta fundamental para comprender las elecciones, percepciones y representaciones de estas madres sobre la maternidad, la guerra y la paz en un tiempo, espacio y contexto determinados, porque como ha señalado el feminismo pos estructural, las identidades son múltiples, y como tales aparecen dotadas de significaciones y símbolos que se construyen en el contexto de unos marcos sociales, políticos, económicos, ideológicos a partir de los cuales los y las sujetos asumen posiciones, representaciones y opciones. Para nuestro caso, estas madres excombatientes desvinculadas del paramilitarismo responden a sus épocas, a su contexto, tienen una historia, y hoy con esa historia construyen un presente y un futuro.

En relación a lo anterior es necesario responder a las preguntas ¿Quiénes eran esas mujeres - madres antes de la vinculación al grupo armado? ¿Dónde habitaban? ¿En qué contexto cultural, social y económico realizaban y vivían su maternidad? ¿Cómo explican las causas de la guerra? ¿Por qué participaron de ella? ¿Quiénes son los responsables de la misma?

Durante el proyecto de investigación escuchamos las voces de aproximadamente treinta mujeres desmovilizadas de los grupos paramilitares entre el 2003 y el 2006. La gran mayoría de estas mujeres tienen en común el hecho de ser jefas de hogar sin compañero, madres solteras, víctimas de la violencia estructural, violencia intrafamiliar y la violencia conyugal - cuando tenían compañero-; con muy bajos niveles educativos; sin trabajo; habitantes de cabeceras urbanas y zonas rurales de municipios pequeños ubicados 
en la periferia de departamentos ubicados en el sur, norte o centro del país donde la presencia del Estado es escasa y frágil.

Apoyadas en las voces ${ }^{6}$ de aquellas mujeres que siendo madres optaron por vincularse a los grupos paramilitares, intentaremos dar cuenta de su visión sobre la maternidad, su participación en los grupos armados, y sus ideas sobre la guerra en y la paz en Colombia.

\section{Madres y Maternidad(es) en la exclusión... ¿causas y responsables de la guerra?}

La vida mía fue muy trágica, desde jovencita, desde niña, nunca tuve una infancia, mi mamá era madre soltera, tuvo cuatro hijos, yo era la menor y mi mamá era alcohólica, nos maltrataba, a la edad de 9 años me llevaron a una casa de familia a cuidar unos muchachitos de una familia rica aquí en [...], de ahí me llevaron a Bogotá a trabajar también en una casa de familia, allá me estuve hasta los 16 años,... me vine otra vez a buscar a mi mamá porque pensé que ella podía haber cambiado, no, estaba peor. Conocí el amor de mi vida porque pensé que esa era mi salvación, casarme, yo dije ahora si voy a salir de todos mis problemas, casándome y mentiras, me casé con el padre de mis hijos que es con el que tengo los tres hijos, me casé por la iglesia con él, enamorada, me fui para el Sur de Bolívar, y mentiras que no era como me lo habían pintado que el matrimonio no le soluciona la vida a nadie... él era una persona súper egoísta, vivía amenazándome, a él le tuve tres hijos. (Testimonio mujer desmovilizada, residente en el norte del país)

Sin caer en generalizaciones, es posible señalar que en Colombia, la representación de lo femenino de mujeres de clase baja, pobres, campesinas, con una profunda tradición religiosa, a diferencia de muchas mujeres de clase media, secularizadas, no se ha construido alrededor de la figura de la mujer profesional con proyecto propio, sino alrededor de la figura de la mujer-esposa-madre o mujer-madre, tal y como lo expresa el testimonio arriba citado.

Madres excombatientes ejercen unas maternidades socialmente vividas en condiciones de opresión y subordinación. Estas madres experimentan su maternidad en contextos rurales y urbanos caracterizados por la pobreza y la violencia donde la presencia de los actores armados es muy fuerte, $y$ en donde el control social en algunas de estas zonas, es ejercido por alguno de los dos grupos armados ilegales. Ellas explican las razones de la guerra a partir de su vivencia individual. Son mujeres que no han politizado sus conciencias, sino por el contrario, tienen una conciencia maternalizada. Muchas de ellas no entienden eso que los analistas clásicos de la violencia denominan como de las causas objetivas y estructurales de la confrontación en el país. 
A diferencia de muchas mujeres-madres de la vieja insurgencia en Colombia y otros grupos guerrilleros en la región, que sí politizaron su maternidad, y como madres decidieron participar en la lucha armada para lograr profundas transformaciones sociales y políticas que les brindara mejores oportunidades no sólo a sus propios hijos/as sino a los Hijos de las clases menos favorecidas, las madres desmovilizadas del paramilitarismo justifican su vinculación a los paramilitares por la falta de un empleo que les permita mantener a sus hijos/as, es decir, para cumplir con la función materna de mantenerles del lado de la vida. Es sí se quiere un asunto mucho más individual, no existe en su vinculación un asunto ideológico ni político. La razón es simple, alejar a sus hijos/as de la muerte, y en la dimensión de la maternidad la muerte es la muerte como tal, así como lo que puede simbolizar: desolación, carencia, vulnerabilidad, peligro, agresión, sufrimiento, enfermedad, e imposibilidad de sobrevivencia en cualquier dimensión. (Lagarde, 2006:252)

En un grupo focal con mujeres desmovilizadas de los paramilitares en el norte del país, les preguntamos ¿Cuáles consideran ustedes que son las causas de la guerra que vivimos en el país?, y algunas de ellas respondieron a partir de su experiencia de vinculación, es decir explican la guerra desde su vivencia, no como un problema que tiene unas raíces históricas, políticas, sociales y que se ha transformado a lo largo del tiempo. Leamos a estas madres excombatientes:

La falta de empleo, la falta de formación en el hogar, formar bien los hijos, porque mire que se llega un caso que como no hay trabajo, uno se desespera, esa la causa de que uno se mete en esos grupos, uno busca que en tal parte están pagando tanto, uno se aleja de la familia con tal de mandarle uno a sus hijos algo porque la situación de trabajo está muy pésima aquí. (Testimonio de madre desmovilizada, residente en el norte del país)

Yo también me fui a la guerra por falta de trabajo, porque de pronto mi papá murió, ya quedamos con mi mamá, quedamos solos. Yo tuve un fracaso, me quedé con cuatro niños, para mí eso era muy duro porque mi esposo me maltrataba y yo vi que no podía vivir en maltrato. De pronto alguien me invitó, que estaban incorporando muchachas para trabajar en las autodefensas, y yo dije: voy a medirme para ver cómo es; entonces fui hasta allá. Cuando yo llegué a ese punto, en medio de todo dije: hasta hoy dejé de ver a mis hijos... me dieron tantas ganas de llorar! Yo le pedía mucho a Dios. (Testimonio de madre desmovilizada, residente en el norte del país).

Unas veces son falta de responsabilidades, porque por lo menos en mi caso pues me tocó ingresar allá porque estaba sola, tenía cuatro hijos, no había trabajo, si me ponía a trabajar, me pagaban 100, 150 mil pesos, para uno pagar arriendo, para uno la alimentación de los niños, para el estudio, no le alcanza....allá [en las AUC] le van a pagar más, con eso yo pago para que me cuiden mis hijos, 
ese es el motivo y falta de estudio, porque si uno tiene estudio va a conseguir un trabajo mejor, que si le va alcanzar y tampoco va a ser tan bobito para dejarse tener tantos hijos, porque una persona estudiada no va a tener 5, 7, 8 hijos, sino que uno vive como por vivir, no piensa la vida al derecho, entonces es falta de un trabajo, de una responsabilidad, que uno consigue un marido y no responde en el hogar como se debe, entonces uno tiene y manda la cabeza donde uno pueda respirar, ese es el motivo. (Testimonio de madre desmovilizada, residente en el suroccidente del país)

Estas madres combatientes cuyos rostros conocimos y para cuyas voces tuvimos una escucha activa, están insertas en el binomio mujer-madre. Ellas, por más conquistas y alcances en materia de derechos para las mujeres en Colombia, no han ingresado en el discurso político y mucho menos en la práctica de la autonomía, la libertad y la igualdad. Difícilmente podemos afirmar que para ellas la maternidad sea una opción, por el contrario podríamos decir que es vista como destino.

Estas mujeres sin conciencia de derechos como ciudadanas, viven la maternidad como un hecho individual, y no social. Su hijo/a es su responsabilidad; el padre puede estar ausente, pero ella no. Madres que ven como natural el amor y el instinto maternos, desconocen que la maternidad es un hecho social donde el Estado y sus instituciones tienen un papel fundamental. Es por ello, que sí un actor armado les ofrece un trabajo que les permita cumplir con sus funciones maternas y además de eso les garantiza el cuidado de sus hijos/as, su trabajo en la guerra se justifica.

Me vine sin nada, con mis tres hijos aquí a [...] a buscar a mi mamá, ya mi mamá estaba en una edad más avanzada, ya estaba enferma pero todavía bebía, entonces me hice cargo de mi mamá, llegué aquí a [...] sin trabajo, con tres hijos chiquititos, buscando empleo en una parte y otra, o sea, trabajaba en un restaurante y el desayuno y el almuerzo que me daban me lo traía para dárselo a mis hijos en la noche cuando llegaba porque no tenía de a dónde. Cuando mi mamá murió, un muchacho, un amigo me habló de las organizaciones de Autodefensas, él me dijo que me fuera para allá pero que yo me iba como a cocinar, que me fuera, allá pagaban bien y yo me fui, yo dije: bueno, lo primero que me dieron fue compras para que le dejara a mis hijos, me buscaron una persona que me los cuidara, allá le abrían como puertas a uno y yo veía otros horizontes, ya yo veía otro camino para mis hijos. (Testimonio, de madre desmovilizada residente en el norte del país)

Retomando a Cristina Palomar, podríamos decir que para el caso de estas madres, la multiplicación de las necesidades económicas con los hijos a cargo, la vulnerabilidad que supone una crianza en soledad y condiciones de exclusión, crean circunstancias de precariedad que conducen a condiciones humanas explosivas, más aún si consideramos que el sistema 
sexo-género supone que sean las mujeres quienes carguen con prácticamente todo el peso del ejercicio de la maternidad. (Palomar 2004: 14)

Los/las hijas son el centro de estas mujeres. Y de ello dan cuenta varios testimonios recabados en campo:

Para mí los hijos son todo en la vida, la razón de ser, todo, y son los que cada día me dan fuerza para salir adelante. Fueron los que me levantaron porque cuando falleció mi esposo fue muy duro para mí y por ellos seguí, por ellos me levanté, y por ellos cada día me levanto: Señor, ayúdame... Mis hijos son todo para mí. (Testimonio de madre desmovilizada, residente en el norte del país)

Para mí son muy importantes, es poquito el tiempo que me he separado de ellos, yo lucho por ellos y estoy tratando de conseguirme un trabajo porque ahorita estoy necesitada, bastante, tengo un niño en el bachillerato que le piden cosas y la niña la tengo un poco enferma, me ha tocado duro, pero a pesar de eso por mis hijos hago lo que sea. (Testimonio de madre desmovilizada, residente en el norte del país)

De los anteriores testimonios y de muchos otros recabados en diversas regiones del país es posible plantear que estas madres representan una maternidad anclada en el marianismo propio de la identidad latinoamericana, que las lleva a reproducir algunos valores asociados a éste como son la abnegación y el sacrificio; así mismo, se inscriben en un maternidad moral, según la cual sobre ellas cae toda la responsabilidad del comportamiento de sus hijos/as, y a partir de esta última creencia, ellas se consideran a sí mismas y a la familia como actoras responsables de la guerra en el país. En tanto consideran la maternidad y la reproducción como un hecho individual, estas madres combatientes, se asumen sin pensarlo, como las responsables de la transmisión de valores, como las encargadas de señalar el camino correcto y lo que es permitido y qué es lo que constituye una transgresión al orden moral y social.

Lo anterior permite comprender testimonios como los siguientes en respuesta a la pregunta ¿Quiénes son los responsables de la guerra en Colombia? O preguntado de otra manera ¿Quiénes hacen la guerra en este país?, las madres desmovilizadas responden:

Yo creo que la guerra y la paz empiezan desde la casa. Es que la familia es el núcleo de la sociedad, con los principios que uno va creciendo en las etapas de la vida, entonces por la familia es más que todo que le siembran a uno esa semillita, la semillita de la paz, la semillita de la falta de diálogo, la violencia, entonces yo creo que por ahí es que empieza la guerra... por la familia... Yo creo que eso es lo que influye y desde el hogar es que empieza todo. (Testimonio de madre desmovilizada, residente en el nororiente del país) 
Otra madre excombatiente señala como culpable a las mamás por no educar bien a sus hijos, veamos:

Las mamás en ese caso tienen un poco más la culpa, porque a veces le negamos el apoyo que nuestros hijos necesitan, no le damos el cariño y no sabemos sobrellevarlo a como debe ser, sino que trabaja tu y gana tu y miras cómo te defiendes... para mi opinión no debe ser así, porque uno debe apoyar a los hijos o aquel compañero que está mal, y si yo tengo una parte económica buena, debo de colaborarles, debo ayudarlos para que esa persona tenga una vida mejor. (Testimonio de madre desmovilizada, residente en el norte del país)

De esta manera asistimos a lo que señala Molina como la figura de la madre omnipotente, madre idealizada y perfecta que puede lograr resultados perfectos para el desarrollo del hijo y la proveedora del cuidado de la familia. Por el contrario los resultados negativos en el desarrollo del niño, los desordenes psicológicos individuales y los males sociales son debidos a las malas prácticas negativas y ella es culpable por ello... (Molina, 2006: 98), hasta de la guerra.

Finalmente podemos afirmar que la participación de estas madres combatientes en los grupos de autodefensa es una transgresión al sistema sexo-género hegemónico según el cual los hombres son los que van al frente y las mujeres se quedan en el hogar. Pero aunque estas madres combatientes hayan decidido -obligadas por las circunstancias de una maternidad precariamente vivida- ir al frente de batalla, su participación en la guerra, no constituye desde ningún punto de vista una transgresión a la figura de la maternidad hegemónica. Por el contrario, ellas como Madres están cumpliendo un mandato naturalizado en la figura de la mujer. La reproducción social de hijos e hijas es responsabilidad de la madre y ellas lo saben y cumplen con ese mandato.

La maternidad dominante, esencialmente biológica, individual y natural, es en la que se mueven estas madres combatientes que van a la guerra para luchar por la sobrevivencia de su prole. Ellas no son madres abandonadoras o malas madres. Ellas se afirman como buenas madres porque cumplen con su familia.

Mi familia ha sido lo principal en todo. Así haya estado en las autodefensas, donde haya estado, mi familia ha sido siempre lo principal. Por ellos me fui, por ellos volví y por ellos estoy aquí otra vez. (Testimonio de madre desmovilizada residente en el suroccidente del país)

\section{Maternidad(es) en una sociedad en (post) conflicto}

Yo nací sin esperanza, yo soy una joven de 28 años, colombiana, bumanguesa que nací sin esperanza, yo nací en un país en guerra. 
Yo nací y no he visto la paz y eso me hace ser una hija de la desesperanza y yo no tengo hijos es porque no tengo esperanzas de que como vamos, vamos bien y vaya a haber un mundo más justo. (Testimonio de mujer activista de paz residente en el nororiente del país)

El anterior testimonio de una joven profesional, activista de paz de la Ruta Pacífica de las Mujeres aparece fuertemente vinculado a la consigna del movimiento de mujeres por la paz en Colombia -y en otros lugares del mundo- según el cual las mujeres no parimos ni forjamos hijos e hijas para la guerra.

En medio del escalonamiento de la guerra desde mediados de los años 90, muchas mujeres en Colombia -dentro de las cuales me incluyohemos politizado la maternidad, o bien, para en nombre del derecho que tenemos de decidir sobre nuestro cuerpo, nos hemos afirmado en la decisión de no tener hijos en un país en guerra; o para que en nombre del derecho que tienen las madres de ver crecer a sus hijos en un país en paz con justicia social, nos movilizamos por Colombia para exigir al unísono, la negociación política del conflicto armado interno para parar la guerra.

Sin embargo, no todas las mujeres colombianas han dejado de concebirse como la matriz para acercarse a la construcción de sí mismas como sujetos sociales. En un país en (pos) conflicto en el cual muchas de las causas estructurales ${ }^{7}$ que le dieron origen se mantienen, y conviven con otras ligadas a las transformaciones que ha sufrido el conflicto (narcotráfico), mujeres campesinas, pobres y excluidas habitantes de zonas periféricas, no se reconocen como sujetos de derechos. Muchas de ellas, significan la maternidad como un don divino, como el rol más importante de la mujer, como una forma de realizarse como tales. Podríamos afirmar que para la gran mayoría, la maternidad aparece como una esencia, como destino y no como posibilidad. Y en esto, hay una gran responsabilidad de las instituciones políticas y religiosas.

Vivimos en una sociedad que ha especializado a las mujeres en la reproducción social, en la que ser Mujer es sinónimo de ser Madre. En que las políticas públicas dirigidas a las mujeres colombianas, son casi que exclusivamente, políticas para mujeres madres (jefas de hogar, familias en acción, mujer rural con especial énfasis en mujeres cabeza de familia, etc.)

Asuntos como los derechos sexuales y reproductivos y el ejercicio de la maternidad en una sociedad en guerra merecen ser pensados tanto por las organizaciones de derechos humanos, ONG y por las instituciones públicas. Además de visibilizar las violencias basadas en el género, y particularmente la vulneración de los derechos sexuales y reproductivos de las mujeres, jóvenes y niñas por parte de los actores armados, es preciso pensar en el ejercicio de estos derechos en una sociedad en (pos) conflicto, en la que aún en pleno siglo XXI, el Estado, algunos partidos políticos y la(s) Iglesia(s) pretenden seguir controlando el cuerpo de las mujeres en Colombia. 
Recientemente el nuevo presidente del Partido Conservador en Colombia, senador José Darío Salazar planteó la necesidad de una reforma constitucional para prohibir el aborto en cualquier caso. Proposición que cuenta con el total respaldo del Procurador General de la Nación y la Iglesia Católica. Esta propuesta va en contravía del fallo emitido por la Corte Constitucional que en 2006 reconoció el derecho de las mujeres a interrumpir su embarazo cuando éste ha sido producto de una violación, cuando existe una malformación del feto que impide su viabilidad y cuando la vida y la salud de la madre corren peligro. ${ }^{8}$

Estamos lejos de vivir en una sociedad en que la maternidad sea pensada como uno de los hechos de la reproducción sociocultural, que se sitúe en las relaciones sociales, es decir en la sociedad y en el Estado - o en cualquier forma de superestructura jurídica-política -, y en la cultura. (Lagarde, 2006: 247).

Las Madres que van a la guerra para alejar a su hijos e hijas de la muerte, no pueden ser señaladas ni por el Estado, ni por la Iglesia, ni por la sociedad civil como “malas madres”, como tampoco podemos señalar como “madres desnaturalizadas", a aquellas madres que en condiciones de extrema vulnerabilidad y pobreza, abandonan o asesinan a su hijos/as. Antes que señalarlas - porque de juzgarlas se encargará la Justicia- debemos preguntarnos como sociedad, como Estado y como Iglesia ¿qué hemos hecho o qué hemos dejado de hacer para que esto ocurra?

Se hace necesario trascender la definición esencial de las mujeres como ligada al imaginario de la maternidad. Una maternidad a la que además se le exige entrega, sacrificio, amor y renuncia.

De esa noción de maternidad vivida fundamental como responsabilidad de la madre, debemos pasar a entender la(s) maternidad(es) como un hecho social. Las maternidades entendidas social y culturalmente, están localizadas, se viven desde distintas posiciones.

Las maternidades socialmente vividas encuentran sus determinaciones de acuerdo con el nivel de riqueza económica y social, con el acceso al bienestar privado y público, con el ámbito rural o urbano en que ocurren, con las clases sociales, los grupos de edad, la progenitura, la conyugalidad, la filiación, el parentesco, la relación laboral, o el prestigio de quienes se ven involucrados en ella (Lagarde, 2006: 250)

Es importante comprender que la maternidad y las responsabilidades que de ella se desprenden no son algo que corresponda sólo a las mujeres. Es una función simbólica y social, que debe ser pensada como,

La tarea social de reproducción de sujetos sociales que, por lo tanto, no puede estar solamente en manos de las mujeres, quienes por otra parte, pueden no tener las aptitudes, deseos o habilidades para criar 
sujetos sociales capaces de convertirse en ciudadanos plenos. En este sentido, la sociedad en general y el estado en particular, debería asegurar las condiciones óptimas para que esta labor se realice de la mejor manera posible. (Palomar 2005: 20)

Debemos preguntarnos ¿qué pasa en un país en el cual un actor armado ilegal es el que les brinda las condiciones óptimas a las madres para que realicen su maternidad? Recordemos el testimonio arriba mencionado por aquella mujer del norte del país que recuerda que el grupo armado paramilitar le consiguió quien cuidara a sus hijos, y mientras tanto otra en el sur, recuerda como el bloque al que pertenecía, les pagaba el arriendo y proveía el cuidado de sus hijos/as.

Ellos vivían conmigo, no ahí dentro del grupo, pero siempre yo pagaba un arriendo, la organización me pagaba el arriendo, ellos tenían su comida y todo y una persona que estuviera pendiente de ellos. (Testimonio de madre desmovilizada residente en el suroccidente del país)

Función protectora de la infancia y la familia suplida por los grupos paramilitares, para que aquellas mujeres-madres pudieran ingresar al grupo armado contrainsurgente como “obreras de la guerra”. ¿Qué hubiera sido de estas madres si hubiesen tenido un empleo decente? ¿Qué hubiese sido de ellas sí hubiesen tenido apoyo estatal y social para la reproducción de sus hijos/as? ¿Qué hubiese sido de ellas si hubiesen tenido oportunidades de juntarse con otras mujeres en igualdad de condiciones y conversar sobre sus derechos como mujeres?

En un país en transición de la guerra a la paz se hace necesario tomar en cuenta el contexto propio en el que se construye la práctica de la maternidad y en el que las mujeres concretas la viven. Palomar (2005: 54), señala que es necesario tener en cuenta varios factores que le imprimen un sello particular al significado de la maternidad y la experiencia subjetiva de ésta; dichos factores son según esta autora, la extrema pobreza, las políticas demográficas, los usos y costumbres, las políticas públicas en todos los campos, entre otros. Y para el caso colombiano, considero que es fundamental tener en cuenta otros como, la presencia de actores armados en buena parte del país, las políticas de salud sexual y reproductiva y la violación de los derechos de las mujeres, las jóvenes y las niñas.

El Estado y sus instituciones, la iglesia, los partidos políticos, y algunas asociaciones de la sociedad civil deberían trabajar por la politización de las conciencias de las mujeres en el país y no por su maternalización. Preocuparse como lo ha venido haciendo el movimiento feminista en el país por la promoción de la autonomía de las mujeres para que sus elecciones no estén dictaminadas por la sujeción al binomio mujer-madre o mujer-esposa.

Ello implica, transitar efectivamente de una situación de guerra a la paz con justicia social, de género y cultural y en la cual exista el respeto 
total por los derechos humanos, incluidos los derechos sexuales y reproductivos de las mujeres colombianas para que la maternidad pueda ser vista como posibilidad y no como destino. En caso que ésta sea elegida con total libertad y autonomía, pueda ser vivida en condiciones de dignidad que garanticen la no repetición de las historias de muchas madres excombatientes que desprovistas de sus derechos como ciudadanas se convirtieron en "obreras de la guerra" para garantizar la subsistencia de sus hijos e hijas. 


\section{Notas}

${ }^{*}$ Las reflexiones presentadas en este artículo son producto de un proyecto de investigación realizado entre julio de 2007 y agosto de 2010, titulado "Desde Diversas Orillas: Voces de mujeres colombianas sobre DDR, Verdad, Justicia y Reparación. Del reconocimiento de la diversidad a la búsqueda de articulación”, desarrollado por el INER - Universidad de Antioquia, con el auspicio del Centro Internacional de Investigaciones para el Desarrollo CIID- Canadá. Los sectores de mujeres que fueron considerados dentro de dicho proyecto son: víctimas; desmovilizadas de la insurgencia y el paramilitarismo; activistas de paz; y mujeres con cargos de representación política en Senado y Cámara.

${ }^{1}$ El paréntesis es mío.

${ }^{2}$ Para una mayor comprensión del concepto Heteronormatividad reproductiva (HNR) véase Spivak, Gayatri. ¿Por qué los estudios de las Mujeres?. Págs. 15 - 40. Traducción de Isabel Carrera Suárez. En: Nación, diversidad y género. Perspectivas críticas. Colección Cultura y Diferencia. Pensamiento crítico - Pensamiento utópico. Anthropos Editorial, 2010. Barcelona, España. Spivak señala para el caso de la India, la heteronormatividad reproductiva es el axioma que respalda la inmolación de las viudas.

${ }^{3}$ Señalo buena parte, porque creo que no es posible generalizar diciendo que el marianismo puede explicar la identidad de género de LAS mujeres en la región. Mujeres más secularizadas que otras, nos declaramos en contra del ícono de la mujer-madre; pero no podemos decir lo mismo de muchas mujeres, para quienes la religiosidad aparece como un elemento fundamental de su identidad. De ahí que sea necesario considerar, además de las categorías de clase, etnia/raza, edad, opción sexual y procedencia, la religión como categoría de análisis en los estudios sobre las mujeres.

${ }^{4}$ En Colombia por ejemplo el Instituto Colombiano de Bienestar Familiar encargado de la protección de la infancia y la familia se crea en 1968. Nuestro ingreso a la modernidad, al igual que muchos otros países latinoamericanos no se da sino hasta comienzos bien entrado el siglo XX.

${ }^{5}$ Alcoff señala, La definición esencialista de la mujer postula que su identidad es independiente de la situación exterior: [...]. La definición con el concepto de posiciones, por otro lado, pone su identidad en relación con un contexto perennemente cambiante, con una situación en la que unos elementos se entrelazan con otros como en una red: la situación económica objetiva, las instituciones y las ideologías tanto políticas como culturales, etc. [...]. La posición de las mujeres es relativa y no innata, y, con todo, no es "indeterminada". A través de un análisis y una crítica sociales podemos establecer la identidad de las mujeres por la posición que mantengan en una red social y cultural determinada. Quizás no se descubra nada nuevo al afirmar que la opresión de las mujeres está imbricada con su posición en la sociedad, pero mi argumento va más allá. Creo que la propia subjetividad (o la experiencia subjetiva de ser una mujer) y la propia identidad de las mujeres se constituyen según la posición que ocupen. No obstante, con ello no quiero dar a entender que el concepto de "la mujer" esté determinado únicamente por los elementos externos, ni que la mujer sea únicamente el recipiente pasivo de una identidad creada por estas fuerzas. Más bien ella misma forma parte del movimiento de una historia fluctuante, y por tanto contribuye activamente a crear el contexto en el que puede delinearse su posición. [...]. Por lo tanto, el concepto de posiciones tiene una doble vertiente: en primer lugar, [...], el concepto de la 
mujer es un término relativo, que sólo puede determinarse en un contexto (en movimiento constante); sin embargo, y en segundo lugar, la posición en la que se encuentren las mujeres puede utilizarse (más que trascenderse) activamente como un emplazamiento para la construcción de significado, como un lugar desde donde éste puede construirse, y no un lugar donde un significado (el de la feminidad) pueda descubrirse. (Alcoff, 2002:19-20).

${ }^{6}$ Por razones de seguridad se omiten los nombres de las mujeres. Se mencionan algunos lugares siempre y cuando no pongan en riesgo la seguridad de las mujeres.

${ }^{7}$ Entre las causas estructurales tenemos pobreza, exclusión social y política, impunidad, inequitativa distribución de la tierra y corrupción.

${ }^{8}$ Sentencia C-355 de 2006 en la cual la Corte decidió que la prohibición penal del aborto en todas las circunstancias violaba los derechos fundamentales de la mujer. La Corte demostró que estos derechos estaban protegidos por la Constitución colombiana de 1991 y por el derecho internacional de los derechos humanos. La Corte explicó que la prohibición absoluta del aborto para proteger los intereses del feto imponía una carga desproporcionada en el ejercicio de los derechos humanos de la mujer. Véase: http://www.womenslinkworldwide.org/ pub_c3552006.html 


\section{Bibliografía}

Alcoff, Linda (2002), "Feminismo cultural vs. Post-estructuralismo: la crisis de identidad de la teoría feminista”, en: Revista Debates $N^{o} 76$, p. 1920. [En línea]: http://148.202.18.157/sitios/catedrasnacionales/material/ 2010a/cristina_palomar/2.pdf

De Beauvoir, Simone (2005), El Segundo Sexo, Sudamericana, Buenos Aires, Argentina.

Farr, Vanessa (2005), “La desmilitarización con perspectiva de género como herramienta para la construcción de la paz”. Cuadernos INER, Serie Traducciones No. 2. Medellín: Instituto de Estudios Regionales INER, Universidad de Antioquia.

Lagarde, Marcela (2006), Los cautiverios de las mujeres: madresposas, monjas, putas, presas y locas, Universidad Nacional Autónoma de México. Colección de Posgrado, México D.F.

Londoño, Luz María y Nieto, Yoana Fernanda (2007), Condiciones de vida y perspectivas frente a verdad, justicia y reparación de mujeres desvinculadas de grupos paramilitares, y su relación con organizaciones de mujeres de Medellín, Bajo Cauca y Urabá. Informe de investigación. INER - Universidad de Antioquia, auspiciado por la OIM y la Secretaría de Equidad de Género para las Mujeres de la Gobernación de Antioquia, Medellín.

Londoño, Luz María et al. (2010), Desde Diversas Orillas: voces de mujeres colombianas sobre desmovilización, desarme y reinserción, verdad, justicia y reparación. Del reconocimiento de la diversidad a la búsqueda de articulación. Informe académico de investigación. INER - Universidad de Antioquia, auspiciado por el IDRC. Medellín.

Molina, María Elisa (2006), “Transformaciones Histórico Culturales del Concepto de Maternidad y sus Repercusiones en la Identidad de la Mujer”, en: Phykhe, volumen $15 n^{\circ} 2$ Revista de la Escuela de Psicología Pontificia Universidad Católica de Chile, Santiago.

Palomar, Cristina (2004), “Malas madres” la construcción social de la maternidad, en: Debate Feminista, año 15, vol. 30, octubre 2004, México.

Ídem (2005), “Maternidad: Historia y Cultura”, en La Ventana, $n^{\circ} 22$ Revista de Estudios de Género Universidad de Guadalajara, Guadalajara.

Ramírez, Mario Elkin (2002), “Las mujeres y la guerra”, en: Revista Psicología desde el Caribe. Universidad del Norte, Barranquilla.

Roberson, Susan (2010), “Narrativas de localización y deslocalización”, en: Nación, diversidad y género. Perspectivas críticas. Anthropos, Barcelona. 
Sanhueza, Tatiana (2005), “De prácticas y significancias de la maternidad, transformaciones en identidad de género en América Latina”, La Ventana, $n^{\circ} 22$ Revista de Estudios de Género Universidad de Guadalajara, Guadalajara.

Spivak, Gayatri (2010), “¿Por qué los estudios de las Mujeres?”, en: Nación, Diversidad y Género. Perspectivas críticas, Anthropos, Barcelona.

Recibido: 09.12.2010

Aceptado: 03.03.2011 